\title{
Combining Configurable Interaction Anticipation Challenges and Volitional Aspects in the Analysis of Digital Posthumous Communication Systems
}

\author{
Fabrício H. S. Pereira, Raquel O. Prates \\ Departamento de Ciência da Computação - DCC \\ Universidade Federal de Minas Gerais - UFMG \\ Belo Horizonte/MG - Brazil \\ \{fabriciohsp,rprates\}@dcc.ufmg.br
}

\author{
Cristiano Maciel, Vinícius C. Pereira \\ Instituto de Computação, Instituto de Linguagens \\ Universidade Federal do Mato Grosso \\ Cuiabá/MT - Brazil \\ \{crismac,viniciuscarpe\}@gmail.com
}

\begin{abstract}
Digital posthumous communication systems are those that allow users to create messages that will only be sent to the intended recipients after their deaths. In these systems users have to express their wishes through configuration settings which will only take effect in the future, when the user is no longer available. In this paper, we propose a methodology that allows us to analyze posthumous communication systems and focuses on users' decisions and how users can understand their future impact at the moment when they are making such decisions. To do so, we have combined the Semiotic Inspection Method (SIM) with the Configuration for Interaction Anticipation Challenges and recommendations on volitional aspects in digital legacy systems. Such analytical lenses were used to inspect three digital posthumous communication systems: If I Die, Se Eu Morrer Primeiro and Dead Man's Switch. The result of our analysis is a thorough account of the decisions designers have made available to users, as well as how they convey what the impact of these decisions will be when they come into effect. Our discussion of these systems and of the challenges identified contributes to the research and development of digital legacy systems in general. The methodology described is a relevant contribution to research on digital legacy and on digital posthumous communication, and also supports the consolidation of the challenges and recommendations used in this analysis.
\end{abstract}

Keywords- Digital Legacy; Interaction Anticipation; Configuration Settings; Volitional Aspects; Semiotic Inspection Method

\section{INTRODUCTION}

After social networks were first created, there has been a boom in terms of systems configuration settings, due to their varied functionalities. Many computer systems allow users to exchange ideas and information, as well as to share resources and coordinate efforts to fulfill tasks. A way to meet the demands of such a great variety of users and objectives is to allow users to configure system settings according to their needs.

A specific context where configuration settings play an essential role is that of death-related technologies, which have recently drawn attention from researchers and system developers. Research topics in that area involve support to decision making about digital legacy [20],[18] support to the bereaved [14],[15] or guidelines and relevant aspects for the development of systems that deal with death-related issues [9],[11],[12],[14]. Among those topics, we herein highlight users' volition (decisions and choices) towards their digital legacy [11].

When designing a configurable system, the designer must define what configuration settings will be available for the users and how they will affect either their interaction with the system, or the interaction among different users through the system. According to Maciel [11], system projects must consider volitional elements, that is, allow users to choose and define the fate of their digital legacy via system. However, there is a challenge in the design project of configuration settings when the effects of those configurations are over the long-run, and not immediate [19], because that requires interaction anticipation. In the domain of digital legacy, there is a great deal of overlapping between volition and long-term configurations, since a user's decisions impact on actions that will be carried out when he is no longer present. Thus, we question: are designers paying enough attention to the anticipatory nature of volitional aspects in death-related applications?

In this paper, we explore the future impact of configuration settings in the domain of posthumous communication. By "digital posthumous communication" we refer to the process of delivering, after a user's death, a digital message left by $\mathrm{him} /$ her to others [8], as seen in Fig. 1. In our analysis, we focus on two different perspectives: how designers help users understand the future impacts of configuration settings; and recommendations for designers to define requirements related to volitional aspects within the domain of digital legacy. Our main goal is to investigate how these perspectives can contribute to the analysis (and design) of digital posthumous communication systems. 


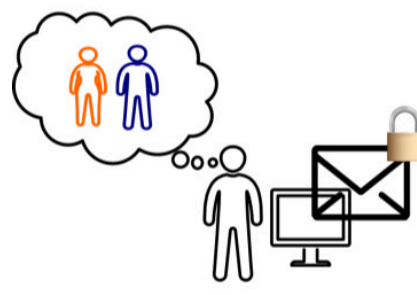

(a)

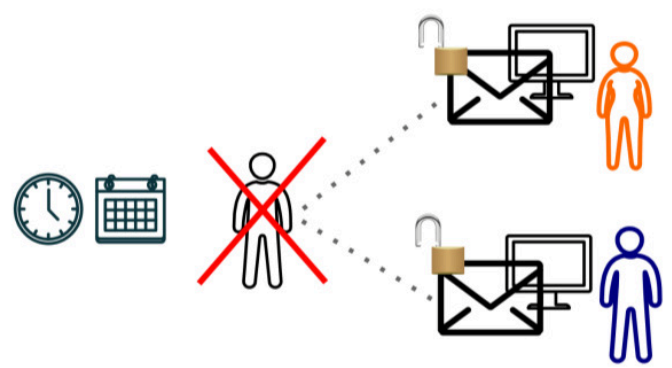

(b)

(c)

Fig. 1. A representation of how a digital posthumous communication system works. The account owner chooses the users who will receive messages in the future, and the messages are stored (inaccessible to the recipients) (a) until the moment of delivery. Later, the system discovers the account owner is inactive (b), so it sends the messages to their respective recipients (c).

To do so, we selected and analyzed three tools that allow users to send posthumous messages to family and friends: If I Die $^{1}$, Se Eu Morrer Primeiro ${ }^{2}$ ("If I Die First", in Portuguese) and Dead Man's Switch ${ }^{3}$. Each system was inspected according to the Semiotic Inspection Method (SIM) [3],[4], focusing on configuration settings for future scenarios [19] (as previously done in [20]) and on recommendations on volitional aspects in digital legacy systems [11].

As results, we present a thorough analysis of these three tools and the particular features made available to users by the designers of each system. Furthermore, we discuss the differences between these systems so as to reflect on the management of posthumous messages.

The article is organized as follows: the next section presents related works that focus either on future impacts of configuration settings, or on the use of technology in deathrelated contexts. Next, we present the Semiotic Inspection Method, the challenges designers face to address interaction anticipation, and volitional elements in web applications. In the methodology, we also describe how SIM was carried out combined with the challenges for interaction anticipation and with volitional elements. Finally, we show the results of our research, discuss our conclusions and propose future works.

\section{RElATED WORKS}

In this section, we present related works grouped into two main categories. The first group includes works about configuration settings in collaborative systems and their impacts over time; the second group includes works about the management of digital legacy.

Although there are many works about flexibility in collaborative systems (e.g. [13]), few of them address the impacts of configuration settings over time. Wulf and Golombek [22] stated the need to provide users with an exploration environment so they can experiment with and understand the impact of their configuration settings on others,

1 https://ifidie.org/. (Last access: June 2016).

2 http://www.seeumorrerprimeiro.com.br/. (Last access: June 2016).

3 https://www.deadmansswitch.net/. (Last access: January 2017) as well as test the results of configuration settings defined by other users. To do so, the authors developed and evaluated an information exchange system where each user could configure what kind of information he/she wanted to share, and what kind of information he/she wanted to receive. By means of that exploration environment, users could understand the results of their configuration settings and those configured by other users.

Pereira Jr, Xavier and Prates [17] explore users' understanding of different interactive paths that could be enabled based on their configuration settings. To do so, they investigated Facebook users' understanding of the effects and possibilities triggered by different configuration settings related to photo posting. The authors implemented a simulator that allowed users to explore different interactive paths based on their settings and actions that these settings enabled other users to take. They concluded that such a resource allowed users to better understand the potential impacts of their decisions regarding their configuration settings.

Prates, Rosson and de Souza [19] present an overview of what it means to help users anticipate consequences of interaction in digital systems. According to the authors, when configuration settings may lead to different interactive paths, it is necessary to help users anticipate them, so they can make informed choices. With such a perspective, the authors inspected Google Inactive Account Manager [20][21], a tool that allows Google users to configure the fate of their data in case their accounts become inactive. Thus, Google Inactive Account Manager is an example of the many environments recently developed to address digital legacy.

Other system projects and research projects on the relation between technology and death focus on helping users decide what to do with their digital legacy [5],[18]; on the stewardship of someone else's legacy [1]; on recommendations for systems related to bereavement and death [9],[11],[14]; and on digital legacy within the legal sphere [10]. There has not been much work focusing on digital posthumous communication, and the ones we have found have focused on a location based memory shared communication [6] and exploring the perspective of potential receivers of posthumous messages [8].

Designing and studying death related systems involves affective and cultural elements, including taboos on death and 
mortality [9],[12]. Although there is a growing research interest in this area, Maciel and Pereira [12] argue that there is still much to be done, including HCI issues, which they grouped into four categories: (i) research on death in digital environments; (ii) issues related to data management; (iii) users' diversity and different approaches to death; and (iv) new interactive and communicative practices related to death.

In this paper, our focus is to analyze configuration settings that have impact over time in terms of posthumous communication, based on the challenges for interaction anticipation [19]. Thus, our goal is to confirm the results discussed in [20],[21] regarding the use of those challenges (anticipation support, representation, cost $\mathrm{x}$ benefits, conflict negotiation/mitigation and definition of default values) as analytical tools for systems that deal with interaction anticipation. We expect our results to contribute to researches on the use of technology to approach death-related issues, especially considering users' volitional aspects (theme ii, as aforementioned) regarding posthumous communication (theme iv, as aforementioned). The next section presents the methodology applied in this study, along with a description of challenges for interaction anticipation [19] and recommendations for the design of volitional aspects [11].

\section{Methodology}

In order to systematically analyze the systems and the way their designers addressed configuration settings in terms of volitional aspects, we used the Semiotic Inspection Method (SIM) [3],[4]. SIM is an inspection method grounded in Semiotic Engineering theory, and it is aimed at identifying designers' intentions and principles, which are communicated to users through system interfaces.

\section{A. The Semiotic Inspection Method (SIM)}

Semiotic Engineering [2] is an explanatory HCI theory that considers a system's interface as a meta-message sent from designers to users. This message tells the users to whom the system is intended, which goals can be achieved by using the system, and how to interact with it. It is called a meta-message because the designer's message is conveyed through the system-user communication. The designer's meta-message can be paraphrased as:

Meta-communication template: "Here is my understanding of who you are, what I've learned you want or need to do, in which preferred ways, and why. This is the system that I have therefore designed for you, and this is the way you can or should use it in order to fulfill a range of purposes that fall within this vision." [2].

Therefore, Semiotic Engineering methods evaluate the communicability of systems, i.e. whether they transmit their design principles, intentions and rationale to users in a coherent and organized way. SIM is a qualitative and interpretative inspection method which is aimed to assess the communicability of an interactive system. It inspects the metamessage sent by the designer to the users by segmenting the interface into three different $\operatorname{sign}^{4}$ categories, which are

$4 \mathrm{~A}$ sign is anything that means something to someone [ 6 . analyzed separately: metalinguistic signs, static signs and dynamic signs [3],[4].

Metalinguistic signs refer to other signs in the system interface (e.g. help systems or tooltips). Static signs represent the state of the system and can be interpreted irrespective of either causal or temporal relations (e.g. the status of a button). Dynamic signs, on the other hand, represent the behavior of the system through causal and temporal relations (e.g. when a new window opens after the user selects an option from a menu)

In the first three steps of SIM, the interface is analyzed under a segmented perspective, focusing on each category of sign at a time: metalinguistic, static and dynamic ones (in this order). At the end of each step, the Semiotic Engineering specialists reconstruct the meta-message conveyed by the designer, using the metacommunication template as a guide. In steps 4 and 5, the segmented analyses are integrated. In step 4, the meta-messages conveyed by the three sign categories are contrasted and compared, in order to identify eventual inconsistencies and generate a unified meta-message. Finally, in step 5, the system is evaluated. In preparation for SIM, the evaluator must first define the scope of the inspection and the scenarios that will guide it.

In this paper, we analyze the meta-messages conveyed by three posthumous communication systems, focusing on the challenges posed by interaction anticipation and on recommendations on volitional aspects. To do so, we have combined SIM with the interaction anticipation challenges (as proposed in [21]) and volitional aspects. This combination requires the evaluator to analyze and register, at each step of SIM, what the designer is conveying regarding each one of these challenges and volitional aspects. Fig. 2 presents an overview of the methodology adopted.

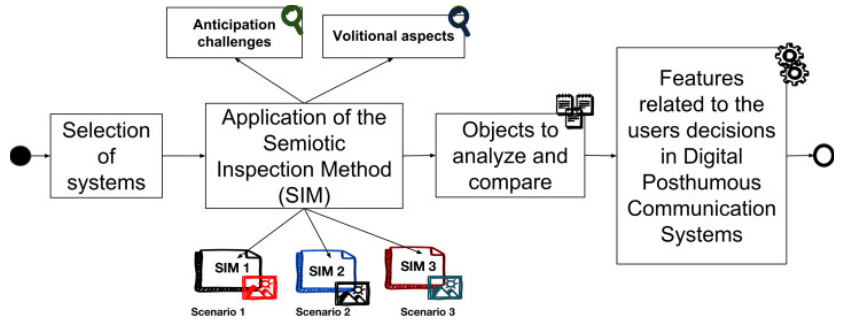

Fig. 2. Overview of methodology adopted.

\section{B. Configuration Interaction Anticipation Challenges}

The Configuration Interaction Anticipation Challenges have been proposed to support collaborative systems designers to reflect upon configuration settings that will impact interactive paths over time and how they affect or are affected by other users [19]. The goal is for designers to consider whether users can understand when they are making decisions regarding settings their actual consequences to them or others in the future. In the context of systems dealing with decision making regarding posthumous actions, these challenges are relevant to be considered since any decision will have a future action as consequence and will impact other people [20],[21]. We next present a brief description of the configuration interaction anticipation challenges [19] (TABLE I. ). 
TABLE I. DESCRIPTION OF THE ANTICIPATION CHALLENGES [19].

\begin{tabular}{|c|l|}
\hline Challenge & \multicolumn{1}{c|}{ Description } \\
\hline $\begin{array}{c}\text { Anticipation } \\
\text { support }\end{array}$ & $\begin{array}{l}\text { Can users anticipate and } \\
\text { understand the possible impacts of } \\
\text { decisions they make and the } \\
\text { scenarios that might stem from } \\
\text { those decisions? }\end{array}$ \\
\hline Representation & $\begin{array}{l}\text { Is it possible to represent the future } \\
\text { scenarios? How is the interface } \\
\text { language used? }\end{array}$ \\
\hline Costs $\times$ Benefits & $\begin{array}{l}\text { What are the costs and benefits of } \\
\text { representing (or not representing) } \\
\text { future interaction scenarios? }\end{array}$ \\
\hline $\begin{array}{c}\text { Conflict negotiation } \\
\text { and mitigation }\end{array}$ & $\begin{array}{l}\text { If the user's decisions impact other } \\
\text { users, what conflicts arise? And } \\
\text { how can they be mitigated? }\end{array}$ \\
\hline $\begin{array}{c}\text { Definition of } \\
\text { default values }\end{array}$ & $\begin{array}{l}\text { Are default values suggested to } \\
\text { help users? Are they appropriate? }\end{array}$ \\
\hline
\end{tabular}

C. Recommendations on Requirements for Volitional Services

Maciel [11] presents 11 recommendations to help designers address volitional aspects in managing digital legacy aspects in social web systems. By inspecting the recommendations, we identified that 5 of them were sufficiently generic that could be applied to digital posthumous communication systems. TABLE II. presents each of these 5 recommendations that were used in our analysis and identifies each one by the label VR (volitional recommendation) and a number.

It is worth pointing out that the other 6 recommendations were not applicable to the digital posthumous communication context since they were based on specific social web systems characteristics. For instance, they were based on premises that users interact with other users through the system, have access to other users' profile or data, as well as store (some of) their data within the system.

TABLE II. RECOMMENDATIONS ON VOLITIONAL ASPECTS [11]

\begin{tabular}{|l|l|}
\hline \multicolumn{2}{|c|}{ Recommendation descriptions } \\
\hline VR1 & $\begin{array}{l}\text { The user must be alerted to make decisions } \\
\text { regarding posthumous services. }\end{array}$ \\
\hline VR2 & $\begin{array}{l}\text { The system must regularly check if the user is } \\
\text { active, so it can carry out the previously } \\
\text { defined actions. }\end{array}$ \\
\hline VR3 & $\begin{array}{l}\text { The system must allow the user to register } \\
\text { "heirs". }\end{array}$ \\
\hline VR4 & $\begin{array}{l}\text { The system must present cases and examples of } \\
\text { how complex the problem is, within the terms } \\
\text { of use. }\end{array}$ \\
\hline VR5 & $\begin{array}{l}\text { The system must ask the user what actions } \\
\text { should be taken in case his death is notified. }\end{array}$ \\
\hline
\end{tabular}

\section{SIM application}

SIM was carried out by one of the authors, who had academic and research experience with that method. An inspection scenario was created for each system that would be analyzed: If I Die, Se Eu Morrer Primeiro and Dead Man's Switch. The scenarios were not exactly the same because the communication possibilities available in each system vary, as we will see in the next section. Whereas If I Die and Dead Man's Switch permit posthumous communication only by means of written verbal messages, Se Eu Morrer Primeiro allows users to include other media, such as photos and videos. All scenarios considered people who, after a specific event, became worried about their digital legacy and decided to explore the system in order to leave messages to their beloved ones. The scenario below was used to inspect the systems If I Die and Dead Man's Switch ${ }^{5}$.

Scenario: Julia is a young undergraduate student pursuing a Business Administration degree who has been stressed out recently. When reading about a student who died of a heart problem, she became worried about her own health and started to wonder what if it had been her. Julia wondered if the people who she cared about would know what to do with her stuff or whether they would have access to the assets that she would like them to have. Thus, she looked for a web system that would allow her to send posthumous messages and found the system "If I Die".

Then she explored it to see what configuration options were available for her to send messages and leave instructions to the people she would like to.

If I Die and Se Eu Morrer Primeiro were inspected during April and May, 2016, and Dead Man's Switch was inspected in January $2017^{6}$. The systems were chosen after some research on systems related to the Digital Legacy of users. We chose systems aimed at posthumous messaging and that were free (or had a free version).

SIM steps were followed accordingly, taking into account the user's perspective, that is, the perspective of the person who chooses to use the system to leave posthumous messages to others. The perspective of the recipients of those messages, or of other people appointed by the user to inform the system about his/her death was not analyzed in this work. All of the metalinguistic signs available as part of the help system or within the system were inspected. All the screens available to the users and the dynamic signs associated to creating posthumous messages were examined. For each system, all the main aspects of the meta-message were taken note of, especially what was communicated regarding the anticipation challenges and the recommendations on volitional aspects. Next, we present the key points of the meta-message from each system and our analyses.

\footnotetext{
5 The scenario for Se Eu Morrer Primeiro also depicted someone who becomes worried with his own death, and hearing about the system, decides to examine it to see if it would let him send messages to family and friends. The main difference was the short description it included about system itself.

6 Features of the systems presented and discussed in the paper correspond to the current version at the time of its inspection.
} 


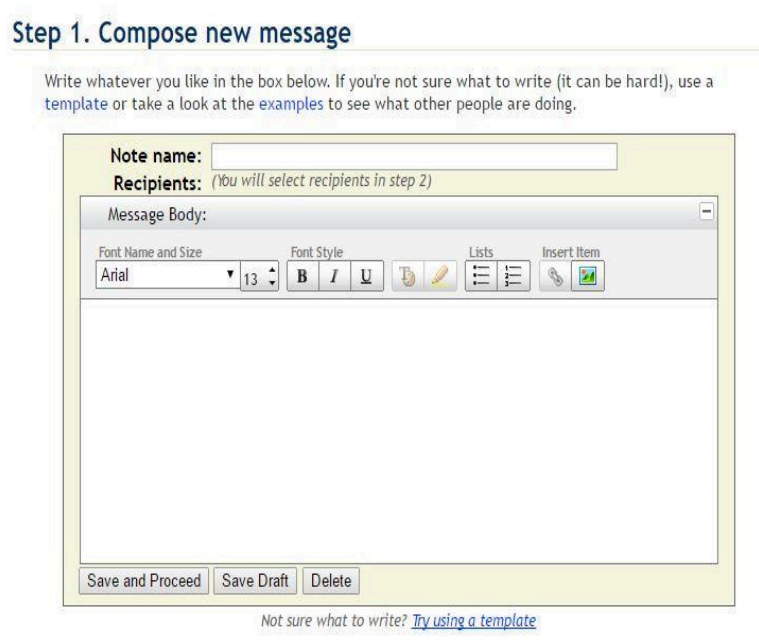

Keep in mind:

- The "Note name" that you choose is for your internal records, so that you can access and update this note at a later date.

- You cannot choose your recipients or change the notification settings until you've saved a draft of your note.

- Your note will not be encrypted until you've finalized and confirmed all the details.

Fig. 3. Screenshot of If I Die tab in which users fill in their posthumous message and decide on its format.

\section{Results of the Semiotic Inspection Method}

Through SIM, we generated the meta-message from the designers of If I Die (Fig. 3), Se Eu Morrer Primeiro (Fig. 4) and Dead Man's Switch (Fig. 5). In the next sub-sections we present the main parts of meta-message of each system. We have used the meta-communication template to organize our results. Thus, we present the content indicated in the template in italics, followed by our results regarding that point ${ }^{7}$.

\section{A. Meta-message from the designers of If I Die}

According to the meta-communication template used in Semiotic Engineering (highlighted in italics) [3],[4], the metamessage conveyed by the interface of If I Die (Fig. 3) would be as follows:

"We (If I Die designers) understand that you (the user)": are someone who would like to send some last words to a friend, relative or acquaintance when these words can be no make sure they will read it eventually.

"Our view about what you want or need to do": You want to write a message to a specific person with any content: something personal, passwords, or instructions on how to access your contacts and/or personal belongings. Maybe you want to send instructions or even an informal will to a specific person. No matter what, you want the message to be cryptographed and safely stored in If I Die. As long as you are

7 Due to space constraints, we have not included in the paper the signs and rationale that have led us to the conclusions presented. We have included one screen from each system, in which users should write a posthumous message (Fig. 3; Fig. 4; Fig. 5) alive, your friends will not be allowed to read the messages. They will only be sent or unlocked when you die.

"How and why you want it to be done": You want to decide who will receive your messages. You also want to be told if anyone tries to read their message before the time defined by you, since the messages are intended to be read only after your death. That is why you want to name some of your friends as safeguards, i.e. make them responsible for informing us when you die. Safeguards will not have any access to your messages. They are only named by you to validate the future information about your death.

"This is the system we (If I Die designers) designed for you, and this is how you can or should use it in order to fulfill a range of purposes that fall within this vision":

You will write and save digital messages for your friends and acquaintances. You can write whatever you want. We provide you with a blank document (see Fig. 3). We will store your message safely cryptographed, with a special password created by you. Every time you write a message, you can send an e-mail to the person to whom the message is intended and tell him or her about it. This additional e-mail tells the recipient there is a message to him/her (the e-mail can be configured within our system), and we will add to it some instructions on how to access the message in case you die.

You must also invite some people to be the safeguards of your messages. Together with the invitation, the safeguards will receive another message written by you, along with instructions on how If I Die works. We will add a link to the email the safeguards receive from us; they must click on that link in case anything happens to you. But we understand safeguards can forget to let us know in case you die, so we give you the option to configure your account to send automatic emails to your safeguards every 3, 6, 12 or 24 months. You can also configure your account to send emails to the posthumous message recipients every $3,6,12$ or 24 months. These emails remind them there are messages for them stored in If I Die, which will be delivered only in the future.

We understand that you do not want anyone to read your messages while you are alive. If anyone tries, If I Die will try to figure out whether you really died and if the messages should really be sent. We will send you an e-mail or text you on a daily basis for two weeks (or as long as you wish). In case you answer those e-mails/text messages, click on the links we send you or log into our system, your messages will remain safe. Otherwise, If I Die will then try to contact your safeguards on a daily basis for two weeks (or as long as you wish, for up to 4 months). If any safeguard answers that you are still alive, your messages will remain unsent. In case neither you nor your safeguards answer in the due period, we will understand your posthumous messages should be sent. If any safeguard informs us of your passing away (by clicking the link they received from us), the system will try to get in touch with you or any other safeguard on a daily basis for one month, before you are considered dead. If your death is confirmed, your messages will be automatically delivered to the due recipients. 


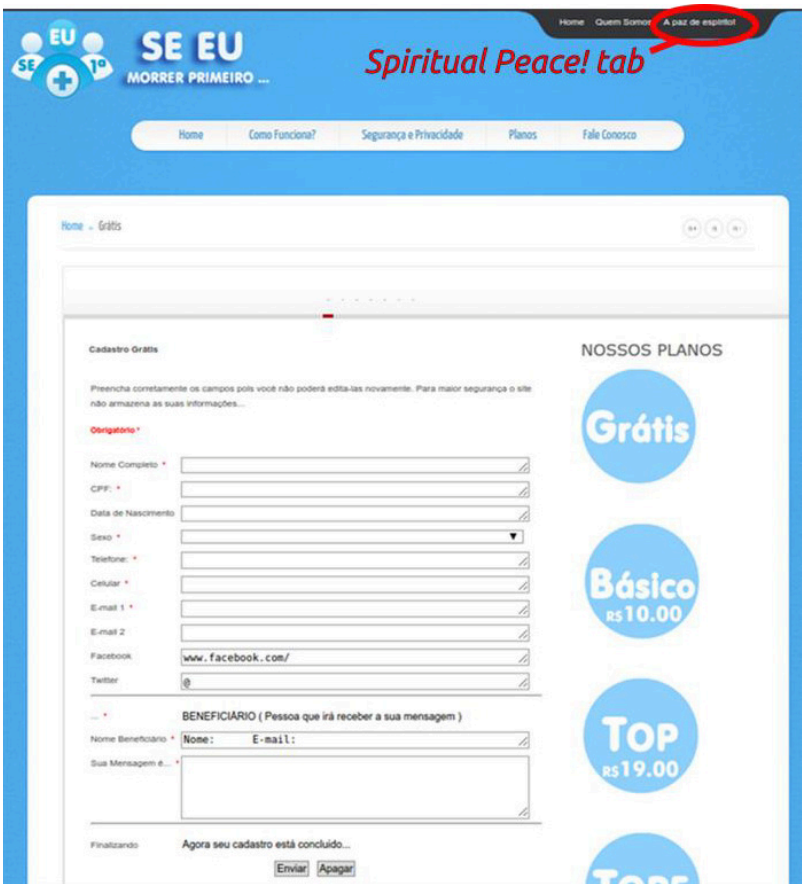

Fig. 4. Screenshot of Se Eu Morrer Primeiro tab in which users fill in their information and write their messages.

\section{B. Meta-message from the designers of $\mathrm{Se}$ Eu Morrer Primeiro}

We present below the meta-message from the designers of Se Eu Morrer Primeiro (Fig. 4), reconstructed through SIM. To test this system, we created an account without the privileges a premium user would have.

"We (designers of Se Eu Morrer Primeiro) understand that you": are someone who wishes to have some last words delivered to special people after your death.

"Our view about what you want or need to do": You want to send your last messages through email in absolute secrecy. You want a digital safe to store secrets while you are alive. However, you want these secrets (including forgiveness messages) to be unveiled after your death.

"How and why you want it to be done": You want to register the names of the people who are to receive your messages after you die. You also want to name two trustworthy people who will be responsible for letting us know in case anything happens to you.

"This is the system we (Se Eu Morrer Primeiro designers) designed for you, and this is how you can or should use it in order to fulfill a range of purposes that fall within this vision":

We offer you a digital place where you can store personal secrets. These secrets will be unveiled after your death to the people you have chosen. For us to do so, you must first choose one of our plans (free or paid ones), which impacts the media and the amount of data we will store, including written texts, images or videos. We know many people have their own frustrations or personal issues, and decide not to talk about some of them in their life time. If you are in doubt about the content of your message, we offer you an explanation on forgiveness and the spiritual peace that may come from it (The user can read the tab "Spiritual peace!" - A Paz de espirito! in Portuguese - on the top right side of Fig. 4).

The platform is safe and all your files are stored in off-line media to prevent anyone from accessing it. We will not leave any piece of your information either on the database of our website or in our servers. Your messages will be cryptographed, changed into codes and sent to two off-line systems in different places.

We will not sell your information, regardless of any reasons, family issues, requests or court sentences. Your data belongs only to you. However, to warrant the security of the data, not even you will be allowed to access it or alter the content of the messages. The only option is to cancel the account and, if you desire, create a new one.

We offer 4 different plans. In the free one, you can only choose a single recipient for one posthumous textual message; that means you cannot add either a photo or a video to your message. Plans that you pay for offer more benefits: they allow you to add more recipients, write messages for individuals and/or groups, send photos and videos. The more you pay, the more benefits you have. Those plans cover you for a period from 1 to 5 years; after that, they must be renewed. When you create your account, you must inform your personal data (name, citizen number, birthdate, gender, phone number and email). After that, you must define who the recipients will be, add their e-mail addresses and write your messages. In the plans that include photos and videos, you can also add a photo for each recipient, and a video for each message intended to a group. However, a group message must be sent to a single recipient, who will then be responsible for sharing it with the others. If none of the people responsible for informing us of your death gets in touch with us, we will try to contact you once a year to renew your plan and know whether you are alive. In case we make sure you are dead, we will send the messages and files to the recipients you chose.

\section{DEAD MaN's SWITCH

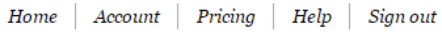

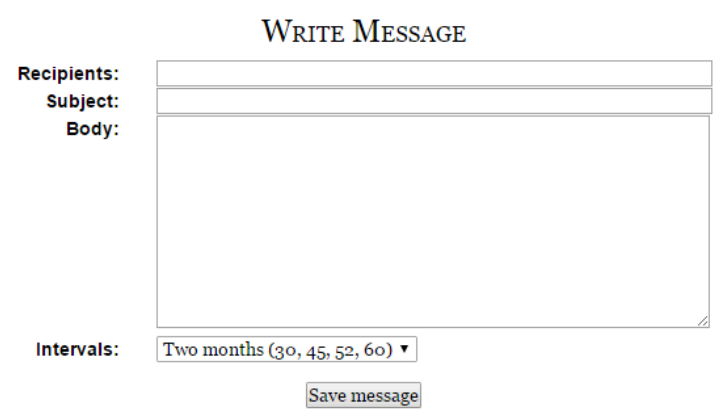

Note: If you're thinking of harming yourself, please seek help. The suicide prevention hotline is there for you.

Fig. 5. Screenshot of Dead Man's Switch tab in which users write their posthumous message. 


\section{Meta-message from the designers of Dead Man's Switch}

We present below the meta-message from the designers of Dead Man's Switch (Fig. 5), reconstructed through SIM. To test this system, we created an account without the privileges a premium user would have.

"We (designers of Dead Man's Switch) understand that you": are a person who wants to leave messages to people you know, but you do not need a strong privacy guarantee.

"Our view about what you want or need to do": You want to send your last messages through e-mail. To do so, you must configure the system so that it will try to get in touch with you within certain periods of time in order to find out whether everything is ok with you.

"How and why you want it to be done": The system will send you emails on a regular basis. All you need to do is click on the link in the email. You do not want third parties to participate in the process; therefore, in case we cannot contact you, your messages will be sent to the recipients you have previously chosen.

"This is the system we (Dead Man's Switch designers) designed for you, and this is how you can or should use it in order to fulfill a range of purposes that fall within this vision":

We allow you to write messages that, after your death, will be sent to whom you wish. By sending you e-mails, our system will try to figure out whether something has happened to you. We will send you e-mails 30, 45 and 52 days after the last time you logged into the system, or after the last time you clicked on one of the links we sent you. If you do not click on the link in at least one of our e-mails, we will send your messages 60 days after the last time we were able to check you were still alive.

On the other hand, you can tell us not to get in touch with you during a specific period of time. If you choose to do so, we will try to get in touch with you 30,45 or 52 days after the non-contact period defined by you expires. For example, if you configure a non-contact period of 10 days, we will send you emails after 40, 55 and 62 days, and your messages will be sent after 70 days, in case you do not reply to us.

Before you write your messages, you must create an account in Dead Man's Switch. As a standard user, you can store up to two messages in your account. Each message can be sent only to two recipients. If you are a premium user, you can send up to 100 messages, with up to 100 recipients each. A premium user can also define other check-up intervals, different from 30, 45 and 52 days.

If you want to see how to create and send messages before you really do it, you can choose the option "test message" for the Intervals list (shown in Fig. 5 under the text box for the body of the message). If you then write a test message, the system will contact you the following day and, in case you do not click on the link we send to you, we will send your test message to the recipient(s) the next day. This way, you can test our system within two days.

But if you are using our system because you intend to kill yourself, we recommend that you look for help. We suggest that you visit a website ${ }^{8}$ that offers free and confidential help to people who are in need. In that website, you will find the testimonials of many people who tried to commit suicide and were convinced not to do it (See Note on the bottom of screen depicted in Fig. 5).

Finally, your messages will be deleted from our servers at the moment they are sent to the recipients. But you can always edit them or exclude them before it happens.

As our service is intended for common use, we discourage you from using it if you need strong privacy guarantees. Our service is also not intended to replace any kind of decision, heritage or letter of attorney.

$$
* * *
$$

Although the three systems belong to the same domain (posthumous communication), they have some evident differences. The meta-messages show If I Die is mainly concerned with making sure recipients will not have any kind of access to the messages before the due time; besides, there is a clear explanation on how the system checks whether the user is dead or not. On the other hand, Se Eu Morrer Primeiro emphasizes emotional and spiritual aspects, such as forgiveness and spiritual peace, even if commercial aspects are pretty clear in the interface. In turn, Dead Man's Switch is more simplistic and merely instructs users to create an account, write a message and decide on how often the system should check whether they are still alive or not. In this system, third parties are not involved in the process of identifying if everything is ok with the user. Even though it is simple, it depicts a concern that users may be leaving posthumous messages because they might be considering suicide and offers some support if this is the case.

\section{AN ANALYSIS OF THE INTERACTION ANTICIPATION CHALLENGES}

We also analyzed the challenges designers face to communicate to users the future impacts of any decisions made in their posthumous communication tools. We focused on how the system asks users what to do in case their death is confirmed [11]. Below, we explain how each challenge [19] is addressed in the three systems.

Anticipation support: Refers to whether the system enables users to anticipate and understand the future impacts of their choices. In If I Die, this support is given in relation to three different moments: (1) when the system explains to users what is done in case there is a chance they are dead; (2) when messages are sent to the recipients; and (3) when safeguards and recipients receive messages reminding them of the user's communicative intentions.

The first support to interaction anticipation is given when the system explains to users how it checks whether they are still alive or not. Through metalinguistic signs, If I Die explains that, in case either a safeguard informs the user is dead, or a recipient attempts to access the message in the system, If I Die will check whether the user is really dead. The system tries to

8 http://suicidepreventionlifeline.org/. (Last access: January 2017) 
get in touch with the user; if it fails to contact him/her, then it will try to contact the safeguards within the period of time previously defined by the user. The user will also receive emails telling him/her that his/her messages will be sent unless he/she logs into the system or clicks on the links in the e-mails sent by If I Die.

The second support to interaction anticipation is given when users write a message to be posthumously sent to a recipient. Users can write a test message with the aid of a preview functionality. When the final message is written, users choose whether or not they want If I Die to inform recipients of its existence; anyway, the message will only be sent after the user dies.

Finally, in the third support to interaction anticipation, If I Die enables the user to schedule automatic reminders to be sent to safeguards and/or recipients every $3,6,12$ or 24 months. Reminders to safeguards are intended to make sure they notify the system in case anything happens to the user. In turn, reminders to recipients are intended to reinforce that there are messages for them in If I Die.

Se Eu Morrer Primeiro does not offer any support to users in anticipating their decisions regarding writing the posthumous messages or choosing trustworthy people responsible for telling the system in case the user dies. When users choose a plan, they are directed to a screen where they must create their account. At that moment, they must also write their posthumous message(s) and include photos and videos, in case their plan allows them to. To add photos, they must upload their respective files; videos, on the other hand, are added by inserting their URLs. There are no metalinguistic signs anticipating what could happen in the future, no test or preview option available, nor any possibility of editing or even deleting it at a later time (the only option is to cancel the whole account)

On its turn, Dead Man's Switch explores metalinguistic signs significantly. Since the first screen of the website, the system presents all the possibilities offered to users, which are communicated through metalinguistic signs organized in FAQs that anticipate possible future scenarios. The user can also click on the "test message" option and see how the process of writing and sending messages works. That option is within the dropdown menu called "Intervals" (Fig. 5). If users write a test message, they will get an e-mail from the system the following day and, if they do not click on the link in the e-mail, the test message will be sent to the recipient one day later. That allows users to experience the whole process that will take place when the system learns of their death.

Representation: In order to represent the future scenarios to users, the three systems introduce new vocabulary, such as "safeguards" (If I Die), "trustworthy contacts" (Se Eu Morrer Primeiro), "uncertain status" (If I Die), "delay in sending" (Dead Man's Switch) etc. The meaning of each word/expression is explained as they come up in the interfaces while users are configuring the settings they want. Most support is offered in natural language through written texts (in the three systems) and by means of practical examples (especially in If I Die). The metalinguistic signs that explain the meaning of specific words/expressions in the interface are usually spread in different tabs, so the user must navigate through them.

Costs and benefits: There are some costs and benefits involved in representing future scenarios, so the user can decide if it is worth the effort. In the systems herein analyzed, there are three main stakeholders involved in the costs and benefits analysis: the sender, the safeguards and the recipients. Senders must create an account, change configuration settings and anticipate the effects of those changes. They must also face the emotional costs of writing posthumous messages. In If I Die, designers make it clear that the goal of the tool is to serve as a blank page, where anything can be written. In $S e E u$ Morrer Primeiro, designers focus on sentimental and affective issues. There is a tab in the website entirely dedicated to the theme of forgiveness and the relief many people get from receiving a message from someone who has recently died. The designers emphasize the possibility of using their tool to send forgiveness messages. In turn, the designers of Dead Man's Switch assume that users of their system could be potential suicides.

Safeguards must also face an emotional cost in the anticipation process. In If I Die, a person only becomes a safeguard if he/she accepts the invitation sent to him/her through the system, which poses an emotional cost of considering the possibility of the user's death. Besides, if a person accepts to be a safeguard, he/she becomes responsible for notifying the system in case the user dies. In Se Eu Morrer Primeiro, there are not many explanations about what it means to be a "trustworthy person". The system says these people will be responsible for giving notice of the user's death, but it does not say how.

In Dead Man's Switch, there are no safeguards or trustworthy people. No third parties are involved in the process of checking whether the user is still alive. However, this may mean a higher configuration and interaction cost for users. The system considers three confirmation periods before considering that the user has died. Users may configure these periods and may also create a delay in which they inform the system to wait a period of time, before starting to count the confirmation time. Also, users have to periodically respond to the systems check on their status.

The designers of Se Eu Morrer Primeiro emphasize the security of the messages to a high extent, so that not even the user can edit them. All settings must be configured, all messages must be written and all files (photos and/or videos) uploaded at the moment the account is created. According to the designers, if users change their mind, their only option is to delete the account and create a new one (the expiry period of the account is from one to five years, depending on the plan). Any mistake in the creation of the account could lead to an unexpected effect, such as sending a message to an unintended recipient, or simply not sending any message at all (in case there is a typo in recipients' contact information, for instance). Thus, any mistake or even a change of mind at a future time about whom to send messages to or what to say would have a high cost to users, since they would be unable to change their decisions. It could even generate financial cost if they had a 
paid plan and came to conclusion that due to the limitations to change their decisions they would rather delete their accounts.

Finally, recipients face the emotional cost of receiving digital messages after the death of a friend, a relative or an acquaintance. If I Die addresses this emotional impact by allowing users to inform the future recipients that they will eventually get a message from them, which is stored in the system. Therefore, when the recipient receives the digital message from the deceased user (some weeks or months after his/her death), he/she will not be surprised by the event. In If I Die, it is up to the user the emotional cost of deciding when and whether recipients should be told about the existence of a message to them. On the other hand, Se Eu Morrer Primeiro and Dead Man's Switch only permit that recipients learn about their messages at the moment they receive them.

Negotiation and conflict mitigation: In the case of posthumous communication systems, users' action may impact other people who may be or may not be users as well. Thus, we analyze the possible conflicts that may arise and possibilities for negotiation. In If I Die, the user must send an invitation to the people chosen to be safeguards, who then have the option to accept it or decline it.

Besides, when users write a posthumous digital message in If I Die, they can also send a message to the recipients, telling them that in the future they will receive a letter, which is for now stored in the system. When the posthumous digital message is finally written, it is protected by a password chosen by the user. In case a recipient tries to read the message before the due time, the system will check whether the user is dead or not. Only if his/her death is confirmed will the recipient be able to read the message. In case none of the people responsible for the security of the message (user and safeguards) answer the emails from the system, the system will assume the user is dead. Consequently, all recipients will receive their messages stored in the system. The fact that a user can name up to 10 safeguards reduces the possibility that someone might read a message before or too much later than the due time. Notice that, differently from Se Eu Morrer Primeiro, users are contacted before safeguards in all possible future scenarios.

A conflict might arise if someone named as a safeguard refused the invitation. In addition to that, there might be a conflict in case a recipient tried to read the message addressed to him/her before the due time. However, both conflicts would be external to the system.

Another potential problem would come up if a safeguard were also a recipient. Safeguards are not allowed to read messages; they can only inform the system whether the user is dead or not, in case the user him/herself does not respond. To minimize any potential conflict, users can extend the period of time the system gives them to respond the checks, before it contacts only the safeguards. Nevertheless, in case that period expires and the user does not answer the emails from the system, the safeguard-recipient could "lie" to the system in order to read the message meant for him/her even though the user is not dead. However, that could only work if the safeguard-recipient were the first safeguard to answer. Optionally, a user who intends to send a message to a safeguard can simply not inform him/her that there is a message for him/her stored in the system. Dead Man's Switch avoids conflicts of interest by not involving any third parties in the confirmation process of the users' status.

In Se Eu Morrer Primeiro, each message can only be sent to a single person, even if it is meant to be read by more than one recipient. These people will only have access to the content in case the person who received the message forwards it to them; in case this recipient decides not to do it (or simply is unable to do it), a conflict could arise. That kind of conflict would not happen either in If I Die or in Dead Man's Switch, since these systems allow the user to send each message to more than one recipient.

The Se Eu Morrer Primeiro designers' decision to limit changes in posthumous communication decisions could lead to conflicts between users and their trusted contacts, since they cannot change the nominated contact. It could also lead to a conflict between users and system administrators. Although the meta-message makes it clear that decisions cannot be reviewed, users could try and argue about the fairness of such feature, especially if they had signed for a long term paid plan.

Definition of default values: The analysis involves analyzing whether the system provides any default values for the configuration of future actions or future scenarios, and if so whether they are appropriate [19]. In If I Die, the invitation emails to safeguards have a default message, but users can edit it if they would like. In case users decide to inform a recipient there is a message for him/her stored in the system, there is also a default message available in the system that they can edit if they wish.

In Dead Man's Switch there are no default values to help users configure their posthumous communication, except the intervals at which the system will send e-mails to the user. As mentioned, there are three confirmation periods for which there is a default value associated that can be changed by users (depending on the user's plan). No other default values are offered to users.

In Se Eu Morrer Primeiro, users fill in a form with their personal information, writes their posthumous messages and uploads files. No default values are presented to the users, not even related to confirmation periods of status like the other systems, since it expects that the trustworthy contacts will inform the system when the user passes away.

\section{ANALYSIS OF VOLITIONAL ASPECTS}

In this section, we present the analysis of the systems regarding the volitional aspects discussed by Maciel [11] and herein presented in the methodology section. As seen, VR1 indicates that the user must be alerted to make decisions regarding posthumous services, VR2 checks for user activity, VR3 indicates that the system must allow the user to register "heirs". Finally, VR4 covers the system present cases and examples of how complex the problem is within the terms of use, and VR5 indicates that the system must ask users what actions should be taken in case their death is notified.

We analyze each recommendation considering that users of the system are already in a context in which they are engaged in making decisions about posthumous communication. 
Therefore, all the systems already comply to recommendation VR5 since their goal is for users to define what messages should be sent to whom in case of their death.

If I Die informs users about the decisions to be made and alerts if there are any potential actions that would lead to a change in their status (VR1), that is, if a safeguard informs the system that the user has died or a recipient tries to access one of the messages stored in the system. If the actions were undue, the user must inform the system that he/she is well, and consequently his/her status should not be changed. Besides, the system checks whether the user is active or not (VR2). It also allows users to choose the recipients of their messages (VR3) and see messages that will be sent (VR4).

In turn, Se Eu Morrer Primeiro, does not show alerts or examples of how to use the tool. The system only asks what to do in case the user dies (VR5) when the account is created. At that moment, the user must also fill in all his data, define safeguards and recipients (VR3).

Dead Man's Switch alerts users by sending them check up emails, so as not to send the posthumous messages before the due time (VR1 and VR2). The system requires users to choose the recipients for their messages (VR3). Dead Man's Switch also helps users understand how complex the whole process is, by allowing them to send test messages (VR4).

Although all three systems are aimed at offering users a specific posthumous service - posthumous communication, our analysis shows that they do not necessarily comply to all recommendations. While If I Die and Dead Man's Switch meet all 5 recommendations, Se Eu Morrer Primeiro only meets 2 of them. The recommendations that Se Eu Morrer Primeiro does not comply with can be perceived as the cause of some of the problems identified with the interaction anticipation challenges analysis.

\section{RELEVANT FEATURES TO BE CONSIDERED IN DIGITAL POSTHUMOUS COMMUNICATION SYSTEMS}

In our analysis of the three systems we have identified features that were relevant to the discussion of the designer-touser meta-communication of these systems. The different decisions presented by designers regarding each of these features had different advantages and disadvantages for users. In this section, we describe these features, since we believe they can support designers or evaluators of posthumous communication systems.

The first three features are related to the status identification process proposed by the system, that is the process adopted by the system to identify when users pass away. Systems must be able to identify the users' change of status, so they can follow their instructions and send out the messages stored in the system. We discuss in the next three features different possible design decisions regarding: the system's role in the process, who are the people involved and the confirmation period needed to minimize the chance of mistakenly changing the users' status.

System's Role in the Process: Systems may take different stands regarding their role in the status identification process. $\mathrm{Se}$ Eu Morrer Primeiro takes a passive role in the verification of users' status, whereas Dead Man's Switch takes an active role in the process, and If I Die takes a mixed approach. In $\mathrm{Se}$ Eu Morrer Primeiro, the system leaves it to a contact indicated by the user to inform it of the change of the user's status. If I Die and Dead Man's Switch take an active role in the process, as they trigger the verification process every time the user is inactive in the system for a pre-determined period of time. If I Die takes a mixed approach, since it may also trigger the verification process based on the user's contact information or actions.

Person responsible for informing of change of status: In our analysis, each system had a different solution for who would be responsible for giving notice to the system that the user passed away. In Se Eu Morrer Primeiro users must inform contact data of people who will play the role of trustworthy contacts and it is their responsibility to inform the system of a change on the user's status. In Dead Man's Switch, users are the only ones responsible to make sure they inform the system that they are well and active once the system has triggered the verification process (when they do not, the system will infer they have passed away). Finally, If I Die takes a mixed approach, it allows users to inform contact data of people who will play the role of their safeguards (but it is optional). During the status verification process, the system sends email to users to check on their status, and only if they do not reply, does the system check with the safeguards. Safeguards may also trigger the verification process by informing the system that the user has passed away. The message recipients may also inadvertently trigger the verification process if they try to read a message before the system has changed the user's status to dead.

When trusted contacts can be included, the designer must also define if these contacts will be invited or nominated. This implies a decision on whether they can accept/decline the invitation (If I Die), or if they are simply nominated by the user and do not have the chance to decline the role, at least not through the system (Se Eu Morrer Primeiro).

Confirmation period: A confirmation period is the period of time the system will take to confirm that user status has changed, namely, that the user is (considered) dead, which adds a temporal dimension to the status identification process. Only once the confirmation time is over, does the system consider that the user is dead and sends out the defined messages associated to his/her account.

If I Die does not count the time trying to contact users as part of the confirmation period. Only after reaching the limit period of time trying to contact users, does it try to contact the safeguards and start the countdown on the confirmation time. Dead Man's Switch breaks the deadline for confirmation period into intervals at which the system will send e-mails to the user in order to check whether he is still alive. Those intervals are counted from the last time the user logged into the system or answered the verification e-mails sent to him/her.

Users' Change of Decisions: Designers should reflect on how definite users' decisions should be. As a digital posthumous communication system involves future scenarios that will take place within an indefinite period of time, it would make sense to allow users to change their minds regarding their decisions 
and edit them at any moment. That should include changing safeguards' contacts, editing contents in the posthumous messages, deleting messages etc., as in If I Die and Dead Man's Switch. On the other hand, Se Eu Morrer Primeiro only allows the user to write/edit messages at the moment the account is created.

In addition to that, users should also be allowed to alter the configuration settings related to the intervals at which the system checks their status. If those settings cannot be altered, the user may simply abandon the system, as he may be dissatisfied with the number/frequency of emails, which could end up being perceived as spam.

Possibility to use different media in posthumous messages: The designers must define what kind of media will the system be able to send as posthumous messages, ranging from written texts (If I Die and Dead Man's Switch) to photos and videos (Se Eu Morrer Primeiro), or audio files.

Reminders and alerts to users and safeguards: Designers should consider which alert messages are interesting to send and to whom. For instance, the status verification message intends to check the users' current status (dead or alive). Thus, designers should decide how often the system will contact the user and/or safeguard to verify the users' status and how long it will give them to reply. In If I Die and Dead Man's Switch the user defines the intervals of the checkup e-mail. In Se Eu Morrer Primeiro, informing the system of a change of status is solely the safeguards' responsibility.

If I Die also sends (i) emails to inform users of any attempts to read stored messages before the due time; (ii) reminders to safeguards, so they do not forget to inform the system in case the user passes away; and (iii) to recipients, so they know there is a message for them stored in the system. However, unlike other applications [21], none of the three systems sends messages to users reminding them of the decisions they took. It might be interesting to consider in which situations such a message could be interesting to users.

\section{CONCLUSIONS}

In this paper, we analyzed the main characteristics of three digital posthumous communication systems, focusing on the future impacts of configuration settings and volitional aspects. To do so, we used the Semiotic Inspection Method [3],[4], the anticipation challenges [19], [20] and the recommendations on volitional aspects in digital legacy systems [9], [11] to identify the meanings conveyed by the designers of If I Die, Se Eu Morrer Primeiro and Dead Man's Switch.

The methodology adopted - SIM combined with the configurable interaction anticipation challenges and volitional aspects - allowed us to present a detailed account of design decisions for each system. Based on the user's perspective, we explored how each one of the challenges was addressed in each system, discussing impacts of the different design decisions taken by the designers. Although the trusted contacts' (or safeguards) and recipients' perspectives were not fully analyzed, design aspects about the users' decisions regarding their indication and the impact of users actions on them were discussed.
Regarding the application of configurable interaction anticipation challenges, it is noteworthy that, although the definition of each challenge is independent of the others, a single design decision may impact more than one challenge. For instance, the Se Eu Morrer Primeiro designers' decision not to let users change any of their decisions, besides representing a significant cost for users, may as well generate conflicts between users and their trusted contacts or even system administrators.

The research on digital legacy systems in general, and posthumous digital communication is still very recent [8], [9], and methods, guidelines or recommendations that focus specifically on this context are being proposed [9],[11][14][21]. Therefore, the application of the methodology adopted per se is a contribution, since our results confirm the relevance of using the configurable interaction anticipation challenges (which apply to other domains [19] as well) in the context of recommendations on volitional aspects [11].

Digital posthumous communication systems allow users to write messages about any topic they want, which might include something personal, passwords, instructions on how to access their contacts and/or personal belongings, or even an informal will to a specific person. There are only a couple of other works that focus on digital posthumous communication [6][8]. Jamison-Powell et al. [8] explored conflicts of interest that may emerge between the living and deceased consumers of posthumous communication at social networks (they specifically discussed the system DeadSocial ${ }^{9}$ ). On their turn, Hall et al. [6] proposed a concept for a ubiquitous service that would allow memories to be saved and stored during an individual's lifetime, and later, after death, for those memories to be published to family and close friends and be experienced at the specific geographic location where they were created.

Our work contributes to the research on digital posthumous communication systems as it (a) discusses and illustrates how the design decisions can be analyzed and considered by the perspective of the configurable interaction anticipation impact, which can support designers in considering how to address each of the challenges; (b) identifies features that are relevant to these systems, and what aspects designers should think about their proposed solution, illustrating how the systems analyzed dealt with each of the features.

Although, we have discussed important aspects that must be considered in systems for the domain of digital posthumous communication, there are number of other issues that are relevant and were not in the scope of this work. Issues such as privacy, security and when messages must be sent are decisive for those applications. According to Maciel et al. [10], it is also necessary to consider data temporality, as human relationships and contact information tend to change over time. Finally, those systems pose challenges to succession law [10] since users can decide to include passwords, responsibilities and informal wills in messages to recipients who are not legally heirs.

9 DeadSocial allows users to plan messages that they would like to send over time through their social network accounts to other users, after they are deceased (see http://deadsocial.org - Last visited April 2017) 
As to suggestions for future works, it would be interesting to apply SIM based on the trusted contacts' and recipients' perspectives of the system. That would require evaluators to user a number of different accounts and simulate the death of the user (which would require evaluators to wait at least the minimum amount of time associated to the confirmation periods). Although we have been able to identify and address aspects regarding their role in the process and what would be some potential impacts for them, a more thorough and complete analysis from their perspectives could point out other issues that were not identified in our analysis of the user's perspective.

It would also be interesting to analyze users' experience with digital posthumous communication systems and how they perceive the communicability of posthumous messaging systems' interfaces. Other applications from the same domain could also be analyzed to check if the characteristics elicited by us could be changed into recommendations for digital posthumous communication systems and digital legacy systems. Finally, besides scientific contributions, our study also brings practical ones, especially useful for the software industry and interface projects for systems of that domain.

\section{ACKNOWLEDGMENTS}

The authors would like to thank FAPEMIG - PRONEX MASWeb (APQ - 01400-14) and CAPES for the partial funding of this project.

\section{REFERENCES}

[1] Jed R. Brubaker, Lynn S. Dombrowski, Anita M. Gilbert, Nafiri Kusumakaulika, and Gillian R. Hayes. 2014. Stewarding a legacy: responsibilities and relationships in the management of post-mortem data. In Proc. of the SIGCHI Conf. on Human Factors in Computing Systems (CHI '14). A157-4166. DOI=http://dx.doi.org/10.1145/2556288.2557059

[2] Clarisse S. de Souza. 2005. The Semiotic Engineering of HumanComputer Interaction. MIT Press

[3] Clarisse S. de Souza and Carla F. Leitão. 2009. Semiotic engineering methods for scientific research in HCI. Morgan \& Claypool Publishers.

[4] Clarisse S. de Souza, Carla F. Leitão, Raquel O. Prates, and Elton J. da Silva. 2006. The semiotic inspection method. In Proc. of VII Brazilian Symp. on Human factors in computing systems (IHC '06). SBC, 148157. DOI=http://dx.doi.org/10.1145/1298023.1298044

[5] Rebecca Gulotta, William Odom, Haakon Faste, and Jodi Forlizzi. 2014. Legacy in the age of the internet: reflections on how interactive systems shape how we are remembered. In Proc.of the 2014 Conf.on Designing interactive systems (DIS '14). ACM, 975-984. DOI=http://dx.doi.org/10.1145/2598510.2598579

[6] Anders Hall, Dragan Bosevski, and Reinell Larkin. 2006. Blogging by the dead. In Proceedings of the 4th Nordic conference on Humancomputer interaction: changing roles (NordiCHI '06), Anders Mørch, Konrad Morgan, Tone Bratteteig, Gautam Ghosh, and Dag Svanaes (Eds.). ACM, New York, NY, USA, 425-428. DOI=http://dx.doi.org/10.1145/1182475.1182528

[7] Nathan Houser and Christian Kloesel. 1992-1998. The Essential Peirce, Vols. I \& II. Indiana University Press.
[8] Sue Jamison-Powell, Pam Briggs, Shaun Lawson, Conor Linehan, Karen Windle, and Harriet Gross. 2016. "PS. I Love You": Understanding the Impact of Posthumous Digital Messages. In Proceedings of the 2016 CHI Conference on Human Factors in Computing Systems (CHI '16). ACM, New York, NY, USA, 2920-2932. DOI: https://doi.org/10.1145/2858036.2858504

[9] Cristiano Maciel and Vinícius C. Pereira. 2013. Digital Legacy and Interaction: Post-Mortem Issues. Springer.

[10] Cristiano Maciel, Vinícius C. Pereira, and Monica Sztern. 2015. Internet users' legal and technical perspectives on digital legacy management for post-mortem interaction. Human Interface and the Management of Information. Information and Knowledge Design. Springer. 627-639.

[11] Cristiano Maciel. 2011. Issues of the social web interaction project faced with afterlife digital legacy. In Proc. of the 10th Brazilian Symp. on Human Factors in Computing Systems and the 5th Latin American Conference on HCI (IHC+CLIHC '11). SBC, 3-12.

[12] Cristiano Maciel and Vinícius C. Pereira. 2015. Post-mortem Digital Legacy: Possibilities in HCI. Human-Computer Interaction: Users and Contexts. Springer. 339-349.

[13] Ivan Marsic and Dorohonceanu Bogdan. "Flexible user interfaces for group collaboration." International Journal of HCI 15.3 (2003): 337-360.

[14] Michael Massimi and Ronald M. Baecker. 2011. Dealing with death in design: developing systems for the bereaved. In Proc. of the SIGCHI Conf. on Human Factors in Computing Systems (CHI '11). ACM, 10011010. DOI=http://dx.doi.org/10.1145/1978942.1979092

[15] Michael Massimi, William Odom, Richard Banks, and David Kirk 2011. Matters of life and death: locating the end of life in lifespanoriented HCI research. In Proc. of the SIGCHI Conf.on Human Factors in Computing Systems (CHI '11). ACM, 987-996. DOI=http://dx.doi.org/10.1145/1978942.1979090

[16] William Odom, John Zimmerman, and Jodi Forlizzi. 2014 Placelessness, spacelessness, and formlessness: experiential qualities of virtual possessions. In Proc. of the 2014 Conf. on Designing interactive systems (DIS '14). ACM, 985-994. DOI=http://dx.doi.org/10.1145/2598510.2598577

[17] Manoel Pereira Junior, Simone I. de R. Xavier, and Raquel O. Prates 2014. Investigating the Use of a Simulator to Support Users in Anticipating Impact of Privacy Settings in Facebook. In Proc. of the 18th Int. Conf. on Supporting Group Work (GROUP '14). ACM, 63-72. DOI=http://dx.doi.org/10.1145/2660398.2660419

[18] Joachim Pfister. 2017. "This will cause a lot of work.": Coping with Transferring Files and Passwords as Part of a Personal Digital Legacy. In Proceedings of the 2017 ACM Conference on Computer Supported Cooperative Work and Social Computing (CSCW '17). ACM, New $\begin{array}{llll}\text { York, NY, USA, } & 1123-1138 . & \text { DOI: }\end{array}$ https://doi.org/10.1145/2998181.2998262

[19] Raquel O. Prates, Mary Beth Rosson, and Clarisse S. de Souza. 2015 Interaction anticipation: communicating impacts of groupware configuration settings to users. Proc of IS - End-User Development. Springer. 192-197.

[20] Raquel O. Prates, Mary Beth Rosson, and Clarisse S. de Souza. 2015. Making Decisions About Digital Legacy with Google's Inactive Account Manager. Proc .of INTERACT 2015. Springer. 201-209.

[21] Raquel O. Prates, Mary Beth Rosson, and Clarisse S. de Souza. 2016 Analysis of Configuration Decision Space Over Time: The Google Inactive Manager Account Case. Proc. of the Brazilian Symposium on Human Factors in Computer Systems (IHC 2016). SBC, 10 pp.

[22] Volker Wulf and Björn Golombek. 2001. Exploration environments: concept and empirical evaluation. In Proc. of the 2001 International ACM Conf. on Supporting Group Work (GROUP '01). ACM, 107-116. DOI=http://dx.doi.org/10.1145/500286.500304 